\title{
Mentoring for Civil Engineers
}


Downloaded by [] on [26/04/23]. Copyright @ ICE Publishing, all rights reserved. 


\section{Mentoring for Civil Engineers}

\section{Patrick Waterhouse}

Bowdon Consulting Ltd 
Published by ICE Publishing, One Great George Street, Westminster, London SW1P 3AA.

Full details of ICE Publishing representatives and distributors can be found at:

www.icebookshop.com/contact.aspx

Other titles by ICE Publishing:

Initial Professional Development for Civil Engineers,

Second edition

Patrick Waterhouse with Harry Macdonald Steels.

ISBN 978-0-7277-6098-2

Successful Professional Reviews for Civil Engineers, Fourth edition Patrick Waterhouse and Harry Macdonald Steels.

ISBN 978-0-7277-6100-2

Civil Engineering Procedure, Eighth edition

Institution of Civil Engineers. ISBN 978-0-7277-6427-0

www.icebookshop.com

A catalogue record for this book is available from the British Library.

ISBN 978-0-7277-6430-0

(C) Thomas Telford Limited 2020

ICE Publishing is a division of Thomas Telford Ltd, a wholly-owned subsidiary of the Institution of Civil Engineers (ICE).

All rights, including translation, reserved. Except as permitted by the Copyright, Designs and Patents Act 1988, no part of this publication may be reproduced, stored in a retrieval system or transmitted in any form or by any means, electronic, mechanical, photocopying or otherwise, without the prior written permission of the Publisher, ICE Publishing, One Great George Street, Westminster, London SW1P 3AA.

This book is published on the understanding that the author is solely responsible for the statements made and opinions expressed in it and that its publication does not necessarily imply that such statements and/or opinions are or reflect the views or opinions of the publishers. While every effort has been made to ensure that the statements made and the opinions expressed in this publication provide a safe and accurate guide, no liability or responsibility can be accepted in this respect by the author or publishers.

While every reasonable effort has been undertaken by the author and the publisher to acknowledge copyright on material reproduced, if there has been an oversight please contact the publisher and we will endeavour to correct this upon a reprint.

Cover photo: Way out of the labyrinth. Shutterstock stock image.

Commissioning Editor: James Hobbs

Development Editor: Melanie Bell

Production Editor: Madhubanti Bhattacharyya

Marketing Specialist: April Nagy

Typeset by Typeset by Academic + Technical, Bristol

Index created by Madelon Nanninga-Fransen

Printed and bound in Great Britain by Bell and Bain, Glasgow

Downloaded by [] on [26/04/23]. Copyright @ ICE Publishing, all rights reserved. 


\section{Contents}

Acknowledgements

Glossary and abbreviations

01

Introduction

What are trainees and their mentors trying to achieve?

And why?

ICE's training system

The mechanics of the mentoring relationship

Preparing for the review

Terminology

02

\section{Learning and development}

What is learning and development?

Learning through experience

Initial professional development 9

Learning styles $\quad 9$

Advice on learning $\quad 11$

Detailed techniques for learning through experience $\quad 12$

Learning opportunities

03

The business objectives of learning and

development

Why are business objectives important?

How does learning and development sit with other business objectives?

What business objectives drive senior civil engineers to develop talent?

Does the acquisition of professional qualifications by people contribute to business objectives?

What does our raw material look like?

Generation Z

What other skills are needed?

04

\section{Recruiting the right people}

Recruitment generally

Incoming trainees

Loss of senior expertise

Diversity

Technology

Change

Management structure

Recruitment summary

05

How ICE qualifications support organisation

learning and development

What are employers looking for?

ICE's attributes

Moving goalposts 
How can ICE qualifications support organisations' learning and development objectives?

Leadership and diversity

06

\section{The ICE training scheme}

The ICE training scheme and its role in initial professional development

The attributes

Flexibility across the three classes of membership

Flexibility across the engineering professions

Equivalent objectives

The target

07

\section{Preparing a training scheme}

Why train to ICE standards?

The scheme

The scheme - introductory statement 50

Introduction to the organisation 51

Primary objectives 51

Key personnel $\quad 52$

Quarterly review $\quad 53$

Placements 54

08

Training agreements for the ICE training scheme

Why use training agreements?

Previous experience

Registration of agreement

Target class of membership

Length of agreement

Transfer of agreement

Termination of agreement

Training without an agreement

$09 \ldots \ldots \ldots \ldots \ldots \ldots \ldots \ldots \ldots \ldots \ldots$ The mechanics of ICE's training scheme

The procedures

Supervising Civil Engineer

Delegated Engineer

Annual appraisal

Preparation for an annual appraisal 66

Training review for completion $\quad 67$

Academic assessment $\quad 68$

Summary

10

What should mentors do in theory?

The basics of the mentoring relationship

Mentoring models

The skilled helper

What should we do if the trainee says 'no'? 
What do mentors actually do in civil engineering? 77

Introduction 77

Why is mentoring important? $\quad 77$

$\begin{array}{ll}\text { Consultation } & 77\end{array}$

What do mentors and trainees want for a successful

relationship? 78

$\begin{array}{ll}\text { The beginning } & 78\end{array}$

Working together $\quad 80$

When the going gets tough 82

12

Trainees' reports

What does ICE require? $\quad 85$

Purposes of development reports 86

Triggering the training process 86

Personal library of experience 87

Ability to review $\quad 87$

Ability to report $\quad 87$

Learning from experience $\quad 87$

Backlog of reports $\quad 89$

Common misunderstandings $\quad 89$

$13 \ldots \ldots \ldots \ldots \ldots \ldots \ldots \ldots \ldots$ Mentors' responses to development reports 91

Comments on development reports $\quad 91$

Questions, not answers $\quad 92$

Examples of mentoring dialogue 93

The structure of development reports 95

The content $\quad 95$

Planning 96

The format $\quad 96$

$\begin{array}{ll}\text { Summary } & 97\end{array}$

$14 \ldots \ldots \ldots \ldots \ldots \ldots \ldots \ldots \ldots$ Monitoring progress 9

Progress towards the target 99

Recording progress generally 100

Progress against attributes 101

Brief details under each attribute 102

Objective review of target 103

$15 \ldots \ldots \ldots \ldots \ldots \ldots \ldots \ldots \ldots \ldots$ ICE professional review 105

Roles of sponsors in professional reviews 105

Eligibility to sponsor a candidate $\quad 105$

Overview 106

Sponsors' declaration $\quad 107$

$16 \ldots \ldots \ldots \ldots \ldots \ldots \ldots$ The reviewers 111

Reviewers' approach to the review 112

The review schedule $\quad 112$

Choosing potential reviewers 113 
Training new reviewers

Updating existing reviewers

Availability of reviewers

17

Sponsors' scrutiny of submission documents

Who is eligible to act as sponsor and what does

ICE require?

What must be 'scrutinised'?

The application

The report

General notes on reports

18

\section{Preparation for review}

Introduction

The presentation - visual aids

The presentation - content

Preparation for the interview

The written exercise

19

The aftermath of failure

Hearing the bad news

What the mentor needs to do

Appeals procedure

Retaking the review

Rectifying any problems

The revised submission

Every review is a complete entity

Preparing for success next time

References

Index 
I have been fortunate to be able to work with people who are passionate about the development of professional civil engineers and have been generous with their time and effort.

I have worked with a panel of consultees who represent the profession in many ways. This book would not provide the broad range of advice that it does without their involvement. I therefore thank Lewis Brimmell, Michael Buckley, Jag Chima, Amy Ellis, Jenny Giles, Tom Glovehew, Jason Hyde, Philippa Jefferis, Sarah Jensen, Nushma Juwaheer, Sarah Loughrey, Shiona MacDonald, Emma McNab, Brenda O'Loan, Yuli Doulala-Rigby, Peter Robinson, Natasha Stone and Andy Thompson.

ICE staff have also been of tremendous help and my thanks particularly go to Donna Surgeoner (Membership Manager for Scotland and Northern Ireland) and Malcolm Peake (Membership Development Officer for London and SE England) for their input. Of particular help to me has been Gillian Elvy, Membership Manager for the North of England. She has helped me navigate my way through the Institution's vast array of procedures, tools and advice documents to ensure that this book's description of the administrative duties of mentors is (hopefully) correct.

Last of all, I must thank Mac Steels, author of a previous version of this book, under a slightly different title, 20 years ago, for his continued support and assistance. Some of his advice in the earlier edition of this book survives and is still relevant; in many respects, civil engineers face a similar challenge when leaving university today as they did when his career started. Mentors looking after those trainees also face similar challenges to their predecessors. A good deal of Mac's advice in 2001, based on his 40-odd years of practice, is remarkably prescient in today's industry. Mac has given his time generously to me in getting this book published and I thank him for that.

References to ICE publications are to those that were downloaded on the dates stated in the References section at the rear of this book. ICE keeps those documents up to date and you should therefore ensure that you are working with the most recent edition before relying on 
something stated therein. Check for currency at www.ice.org.uk.

Any errors remaining in this book after all of this help are, of course, mine.

Patrick Waterhouse

March 2020 


\section{Glossary and attribute abbreviations}

CMI
completion certificate

CPD

CPRP

Delegated Engineer

(DE)

development report

ICE

initial professional

development (IPD)

IPD Online

The abilities someone must have to become an ICE member. Trainees must show they've achieved the attributes during their initial professional development and at the professional review. There are nine attributes

Black, Asian and minority ethnic Building Information Modelling The assessment undertaken at the conclusion of initial professional development by those who have not trained under an ICE training agreement

Chartered Management Institute Certificate signed by the SCE and MDO to confirm that initial professional development has been completed continuing professional development chartered professional review progressive

An individual (normally a professionally qualified ICE member) who has been given responsibility, by an SCE to mentor trainees on a day-to-day basis

Reports written by trainees to document progress made towards attaining the attributes. These are submitted to the SCE on a regular basis

Institution of Civil Engineers The career stage when a trainee gains the experience, special skills and professional approach needed to practise as a civil engineer. It bridges the gap between education and professional qualifications. For trainees on an ICE training scheme, IPD is recorded and assessed using IPD Online

The online system hosted by ICE for administering the training agreements, which allows trainees to $\log$ their IPD 


LGBTQ +
MDO
MPR
NEC
partial completion

professional review report

professional review

Supervising Civil Engineer (SCE)

TAGSO

training agreement

training scheme
An acronym for lesbian, gay, bisexual, transgender, queer or questioning and others Membership Development Officer member professional review New Engineering Contract If a trainee leaves an employer before completing a training agreement, the progress made should be recorded by the SCE in IPD Online as a 'partial completion'

Report submitted as part of an ICE professional review

The review of a trainee's attributes by two independent reviewers prior to membership of ICE

An individual approved by ICE and provided by employers to mentor trainees. The SCE will preferably be a professionally qualified ICE member, but it's not mandatory. SCEs will have a good understanding of the process and standards needed to become professionally qualified with ICE, and an active level of personal contact with the trainee. They also make sure trainees get the necessary experience

Training Agreements Online system A formal agreement between an employer and a trainee. The employer agrees to provide support and experience so that the trainee can complete the IPD. The trainee agrees to work diligently to gain experience and document it as required by ICE and the SCE A structured training programme used by employers to help trainees get the experience and skills needed to qualify as professional engineers. An important part of the scheme is the mentoring trainees get from an SCE (and a DE if applicable), who is provided by the employer. 
Trainees' progress on the scheme is recorded and measured using IPD Online

VAK

written exercise visual, auditory and kinaesthetic

As part of the professional review, this is a 2 hour test of the trainee's ability to communicate in written English. The reviewers will draft two questions, one of which must be answered 